\title{
Synthesis of Flexible Aerogel Composites Reinforced with Electrospun Nanofibers and Microparticles for Thermal Insulation
}

\author{
Huijun Wu, ${ }^{1,2}$ Yantao Chen, ${ }^{1}$ Qiliang Chen, ${ }^{1,2}$ Yunfei Ding, \\ Xiaoqing Zhou, ${ }^{1,2}$ and Haitao Gao ${ }^{1}$ \\ ${ }^{1}$ College of Civil Engineering, Guangzhou University, Guangzhou 510006, China \\ ${ }^{2}$ Guangdong Provincial Key Laboratory of Building Energy Efficiency, Guangzhou University, Guangzhou 510006, China
}

Correspondence should be addressed to Huijun Wu; wuhuijun@tsinghua.org.cn

Received 28 December 2012; Accepted 11 April 2013

Academic Editor: Yongcheng Jin

Copyright (C) 2013 Huijun Wu et al. This is an open access article distributed under the Creative Commons Attribution License, which permits unrestricted use, distribution, and reproduction in any medium, provided the original work is properly cited.

Flexible silica aerogel composites in intact monolith of $12 \mathrm{~cm}$ were successfully fabricated by reinforcing $\mathrm{SiO}_{2}$ aerogel with electrospun polyvinylidene fluoride (PVDF) webs via electrospinning and sol-gel processing. Three electrospun PVDF webs with different microstructures (e.g., nanofibers, microparticles, and combined nanofibers and microparticles) were fabricated by regulating electrospinning parameters. The as-electrospun PVDF webs with various microstructures were impregnated into the silica sol to synthesize the PVDF/SiO ${ }_{2}$ composites followed by solvent exchange, surface modification, and drying at ambient atmosphere. The morphologies of the $\mathrm{PVDF} / \mathrm{SiO}_{2}$ aerogel composites were characterized and the thermal and mechanical properties were measured. The effects of electrospun PVDF on the thermal and mechanical properties of the aerogel composites were evaluated. The aerogel composites reinforced with electrospun PVDF nanofibers showed intact monolith, improved strength, and perfect flexibility and hydrophobicity. Moreover, the aerogel composites reinforced with the electrospun PVDF nanofibers had the lowest thermal conductivity $\left(0.028 \mathrm{~W} \cdot \mathrm{m}^{-1} \cdot \mathrm{K}^{-1}\right)$. It indicates that the electrospun PVDF nanofibers could greatly improve the mechanical strength and flexibility of the $\mathrm{SiO}_{2}$ aerogels while maintaining a lower thermal conductivity, which provides increasing potential for thermal insulation applications.

\section{Introduction}

Silica aerogel is a highly porous material with pore diameters in the range of $2-50 \mathrm{~nm}[1,2]$. The nanoporous structure of the silica aerogels having a high porosity above $90 \%$ makes the aerogels a highly thermal insulating materials with a super-low thermal conductivity as low as $0.013 \mathrm{~W} \cdot \mathrm{m}^{-1} \cdot \mathrm{K}^{-1}$. The silica aerogels have well been acknowledged as one of the most attracting thermal insulation materials for wide applications in aircrafts and aerospace, chemical engineering, building constructions, and so forth [3-5]. However, the silica aerogels generally have poor mechanical stability (e.g., low strength and high brittleness) owing to their nanoporous nature and high porosity. The flexural strength of the pure silica aerogel with the density of $0.1 \mathrm{~g} \cdot \mathrm{cm}^{-3}$ was approximately $0.02 \mathrm{MPa}[6]$ and the collapse strength under compression of the silica aerogel with the density of $0.21 \mathrm{~g} \cdot \mathrm{cm}^{-3}$ was approximately $2.5 \mathrm{MPa}$ [7]. The low flexural and collapse strength of the aerogels greatly limited their applications for thermal insulation.

Besides strengthening the aerogel framework by optimizing the sol-gel techniques [8], adding reinforced fibers into the silica aerogels and synthesizing the fiber-reinforced aerogel composites have become one of the most effective methods so as to improve the mechanical properties of the aerogels [2]. Various inorganic fibers [9-11] such as glass fibers, mullite fibers, ceramic fibers, and aluminum fibers were used to reinforce the aerogels. The previous literatures $[9,10]$ showed that the organic fibers could significantly improve the compressing strength of the aerogels. Moreover, the inorganic fibers could improve the shielding ability of the aerogels to the heat radiation at high temperature. However, owing to 
the brittleness of the inorganic fibers, the aerogel composites reinforced by the inorganic fibers were brittle and less flexible. Feng et al. [12] synthesized the carbon aerogel composites reinforced by carbon fibers via the pyrolysis of the resorcinolformaldehyde (RF) aerogels reinforced with oxidized polyacrylonitrile (PAN). Finlay et al. [13] impregnated the 2-mmlength short-cut natural polymer fibers into clay aerogels and achieved 4-time increase in compressive strength while only $20 \%$ increase in density. Compared to the inorganic fibers, the organic fibers have better flexibility so that the organic fibers are advantageous to synthesize flexible aerogel composites.

The previous literatures [9-13] on the aerogel composites focused on the reinforcements of the inorganic and organic fibers with the diameters in dozens of or several microns. The diameters of the reinforced fibers are greatly greater than those of the holes and the particles of the $\mathrm{SiO}_{2}$ aerogels (namely, in several or dozens of nanometers). The great difference in the sizes of the reinforced fibers and the aerogel matrix leads to a great difference of the strains of the fibers and aerogels during the drying process of the fiber/aerogel composites. It often results in great cracks and weak mechanical stability of the fiber reinforced aerogel composites [14]. Therefore, reducing the diameters of the reinforced fibers and decreasing the difference of the sizes of the reinforced fibers and the aerogel matrix may improve the monolith integrity and the mechanical stability of the fiber/aerogel composites.

Electrospinning is a simple and low-cost method for making polymer and ceramic fibers with superfine diameters [15-17]. In recent years, it has attracted an increasing interest in the electrospinning technique owing to the promising properties of the electrospun nanofibers. Various structured and assembled nanofibers have been developed via electrospinning for specific functions and wide applications [1820]. Very recently, $\mathrm{Li}$ et al. [21] developed a type of $\mathrm{SiO}_{2}$ aerogel composite reinforced with electrospun poly(ethylene oxide) (PEO)/Elast-Eon TM (E2A) nanofibers via hybrid film casting and nanofiber electrospinning. Since the electrospun $\mathrm{PEO} / \mathrm{E} 2 \mathrm{~A}$ nanofibers had the diameter of approximately $500 \mathrm{~nm}$ which was significantly finer than common inorganic and organic fibers and more closer to the size of the $\mathrm{SiO}_{2}$ aerogels, the aerogel composites reinforced with the electrospun $\mathrm{PEO} / \mathrm{E} 2 \mathrm{~A}$ nanofibers developed by Li et al. [21] showed intact morphology, little cracks, and good flexibility. However, the size of the flexible aerogel composite specimen prepared by Li et al. [21] was small $(1.307 \mathrm{~cm} \times 1.264 \mathrm{~cm} \times 0.0857 \mathrm{~cm})$. Moreover, the thermal conductivity of the aerogel composites was significanlty increased to $0.0505 \mathrm{~W} /(\mathrm{m} \cdot \mathrm{K})$ owing to the limitation of the fabrication technique. Therefore, although the electrospun nanofibers have been proposed to strengthen the aerogels, the preparation technique of the electrospun nanofibers reinforced aerogel composites with larger size, and lower thermal conductivity has to be further developed.

In this paper, flexible $\mathrm{SiO}_{2}$ aerogel composites reinforced with electrospun PVDF web were synthesized via electrospinning and sol-gel processing. Three electrospun PVDF webs with different microstructures are fabricated and then used to reinforce the $\mathrm{SiO}_{2}$ aerogels. The effects of the electrospun PVDF on the thermal conductivity and the mechanical properties of the $\mathrm{SiO}_{2}$ aerogels composites are evaluated.

\section{Materials and Methods}

2.1. Materials. Tetraethylorthosilicate ( $>98 \%$, TEOS), ethylalcohol (>99\%, EtOH), N,N-dimenthyl-formamide (>98\%, DMF), $N$-hexane (>99\%), and trimethylchlorosilane (>95\%, TMCS) were purchased from Baishi Co. Ltd. (China) and used as received. Hydrochloric acid $(37 \%, \mathrm{HCl})$ and ammonia (25\%, $\mathrm{NH}_{4} \mathrm{OH}$ ) were purchased from Guanghua Co. Ltd. (China) and used after diluted 10 -fold with deionized water. PVDF was purchased from Baishi Co. Ltd. (China).

2.2. Electrospinning of PVDF Web. PVDF solutions with certain concentrations (namely, 18 wt.\%, 23 wt.\%, and $28 w t . \%$ ) were prepared by dissolving PVDF particles in DMF in a water bath at $65^{\circ} \mathrm{C}$ under magnetic stirring for $6 \mathrm{~h}$, followed by cooling to room temperature with continuation of stirring for another $6 \mathrm{~h}$. The PVDF solutions were, respectively, inserted into a plastic syringe with a stainless steel nozzle with the diameter of $1.0 \mathrm{~mm}$ for electrospinning by using an electrospinning apparatus (Model: NEU) from Kato Tech Co. Ltd., Japan. The apparatus consists of a syringe pump for supplying the PVDF solution, a grounded electrode for collecting the fibres, and a DC power for supplying high voltage. In the electrospinning process, the voltage of $13 \mathrm{kV}$ was applied to the stainless steel connected with the PVDF solution. The distance of the nozzle and the collecting electrodes was $15 \mathrm{~cm}$. The electrospun PVDF webs with a certain thickness were collected via electrospinning for about 5 days. The PVDF webs were dried at $80^{\circ} \mathrm{C}$ for $12 \mathrm{~h}$ before being used to reinforce the $\mathrm{SiO}_{2}$ aerogels.

2.3. Preparation of Silica Sol. $100 \mathrm{~mL}$ silica sol was prepared by a two-step acid/base catalyzed sol-gel process. In the first step, TEOS, EtOH, deionized $\mathrm{H}_{2} \mathrm{O}$, and $\mathrm{HCl}$ were mixed in the molar ratio $1: 7: 1: 1 \times 10^{-5}$ and magnetically stirred for 30 mins. The solution was then refluxed for $24 \mathrm{~h}$ at room temperature. In the second step, $\mathrm{DMF}, \mathrm{H}_{2} \mathrm{O}$, and $\mathrm{NH}_{4} \mathrm{OH}$ were added into the stock solution and stirred for $30 \mathrm{mins}$. The final molar ratio of TMOS : $\mathrm{EtOH}: \mathrm{H}_{2} \mathrm{O}: \mathrm{DMF}: \mathrm{HCl}: \mathrm{NH}_{4} \mathrm{OH}$ is $1: 7: 2: 0.25: 10^{-5}: 3.57 \times 10^{-3}$

2.4. Synthesis of $\mathrm{SiO}_{2}$ Aerogel Composites Reinforced with Electrospun PVDF Web. The electrospun PVDF webs were added into the silica sol as framework and the $\mathrm{PVDF} / \mathrm{SiO}_{2}$ composites were obtained. The $\mathrm{PVDF} / \mathrm{SiO}_{2}$ composite gelled to monoliths after $0.5-1 \mathrm{~h}$. The composite gels were kept at room temperature for 2 days for further solidification to form silica monoliths. These monoliths were aged in $\mathrm{H}_{2} \mathrm{O} / \mathrm{EtOH}$ (1:4, vol.) solution for $24 \mathrm{~h}$ and then TEOS/EtOH $(1: 4$, vol.) solution to strengthen the gel network. The water and ethanol solvents in the pores of the wet gel were exchanged with isopropanol and $n$-hexane, respectively. After being immersed in a solution of $10 \%$ vol. TMCS $/ n$-hexane at $35^{\circ} \mathrm{C}$ for about $8 \mathrm{~h}$ for surface modification, the monoliths were washed in $n$-hexane for $32 \mathrm{~h}$. The $\mathrm{SiO}_{2}$ aerogel composites reinforced with electrospun PVDF webs were synthesized by drying the monoliths at $70^{\circ} \mathrm{C}$ for $12 \mathrm{~h}$ followed by further drying at $100^{\circ} \mathrm{C}$ for $12 \mathrm{~h}$. 


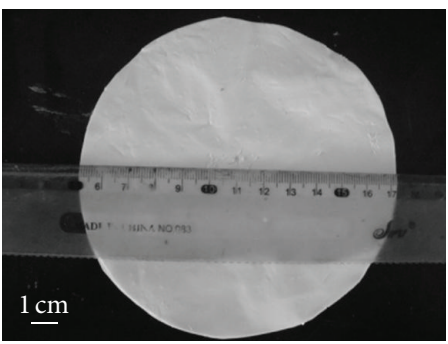

(a)

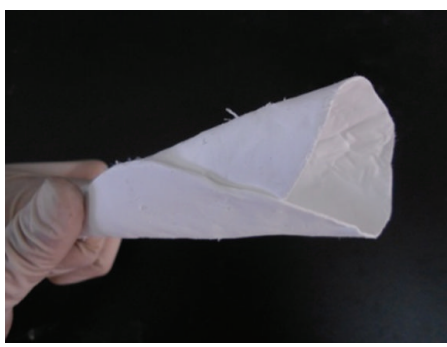

(d)

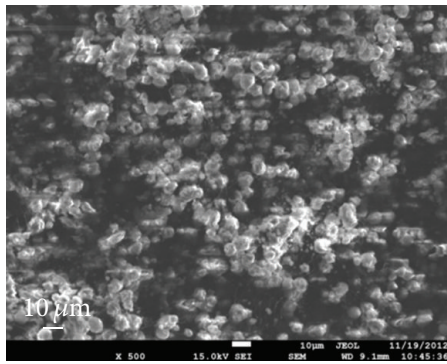

(g)

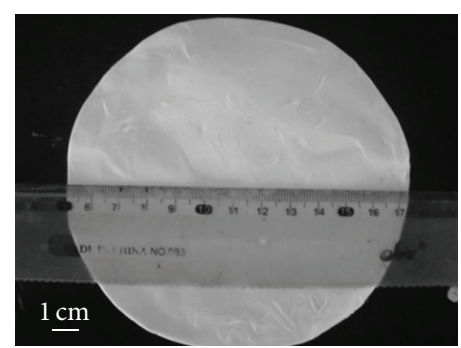

(b)

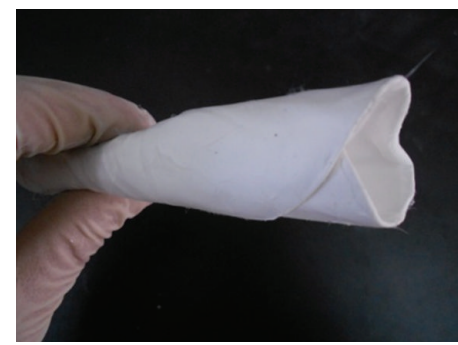

(e)

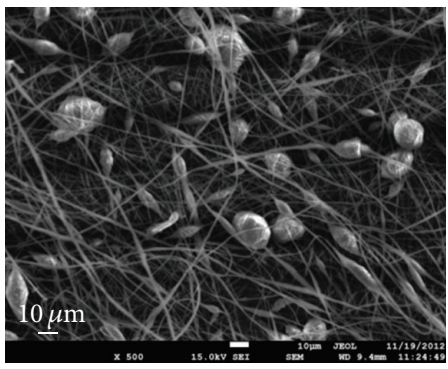

(h)

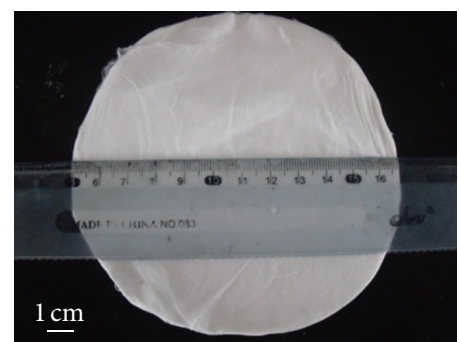

(c)

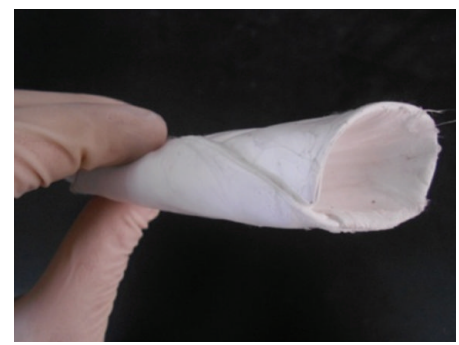

(f)

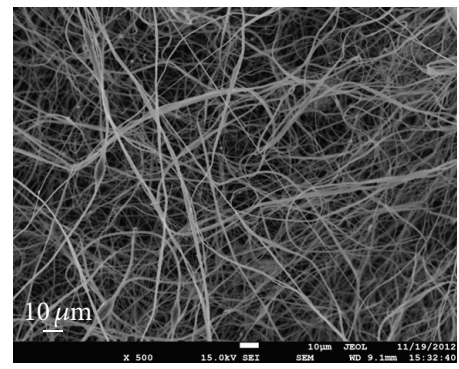

(i)

FIGURE 1: Morphology and microstructure of three electrospun PVDF webs (a, d, and g) microparticles electrospun from 18 wt.\% PVDF; (b, e, and h) combined microparticles and nanofibers electrospun from $23 \mathrm{wt}$ \% PVDF; (c, f, and i) nanofibers electrospun from $28 \mathrm{wt} . \%$ PVDF.

2.5. Instruments and Characterizations. The as-synthesized $\mathrm{SiO}_{2}$ aerogel composites reinforced with electrospun PVDF webs were coated with gold/palladium to be investigated on their morphology and microstructure by using a 1530VP scanning election microscopy (SEM, LEO, Germany). The thermal conductivity was measured by a TPS2500 thermal conductivity apparatus (Hot Disk, Germany) in terms of a transient plane heat source method at room temperature. The testing power and period of the thermal conductivity apparatus were $10 \mathrm{~mW}$ and $20 \mathrm{~s}$, respectively. The thermostability of the aerogel composites was measured by using a TGA400 thermal gravimetric analyzer (TG, PerkinElmer, USA) at the heating rate of $10^{\circ} \mathrm{C} / \mathrm{min}$, respectively. The surface hydrophobicity of the aerogel composites was determined using a Kruss DSA100 droplet scanning analysis (DSA, Germany) at a static analysis mode.

The bulk density of the aerogel composite was determined by measuring the weight and volume of the aerogel composites. The compression tests of the aerogel composite were carried out on a WHY-50 automatic pressure testing machine (Hualong, China) at a time-displacement model with a loading speed of $2 \mathrm{~mm} / \mathrm{min}$. The bending modulus of the aerogel composites was investigated with a threepoint flexural bending method on a CMT6104 universal testing machine (Sunthink, China) with a loading speed of $5 \mathrm{~mm} / \mathrm{min}$ at room temperature [9].

\section{Results and Discussion}

3.1. Microstructures of Three Electrospun PVDF Webs from Different Concentrations. Figure 1 shows the morphologies and microstructures of the three electrospun PVDF webs from the different PVDF/DMF solutions with various concentration (namely, 18 wt.\%, 23 wt.\%, 28 wt.\%). Figures 1(a)-1(f) are the optical images of the three electrospun PVDF webs cut in circles with the diameter about $12 \mathrm{~cm}$. It can be observed that the two PVDF webs electrospun from the $23 \mathrm{wt} \%$ and 28 wt.\% PVDF solutions have better integrity and flexibility than that from 18 wt.\% PVDF solution. Figures 1(g)-1(i) show the SEM images of the three electrospun PVDF webs. Three different microstructures (namely, microparticles, combined microparticles and nanofibers, and nanofibers) could be observed which were electrospun from the PVDF solutions with the concentrations of $18 \mathrm{wt} . \%, 23 \mathrm{wt} . \%$, and $28 \mathrm{wt} . \%$, 
TABLE 1: Properties of electrospun PVDF webs from different concentrations.

\begin{tabular}{lccr}
\hline Concentration of PVDF solution (wt.\%) & Microstructures & Properties of electrospun PVDF webs \\
& Density $\left({\left.\mathrm{g} \cdot \mathrm{cm}^{-3}\right)}^{\text {Thermal conductivity }\left(\mathrm{W} \cdot \mathrm{m}^{-1} \cdot \mathrm{K}^{-1}\right)}\right.$ & 0.048 \\
\hline 18 & Microparticle & 0.277 & 0.041 \\
23 & Microparticle/nanofiber & 0.235 & 0.037 \\
29 & Nanofiber & 0.202 & 0.23 \\
\hline
\end{tabular}

respectively. The microparticles with the diameter in several micrometers were obtained via electrospinning from the 18 wt.\% PVDF solution, while the nanofibers with the diameter in several hundred nanometers were obtained from the 28 wt.\% PVDF solution. For the 23 wt.\% PVDF solution both the microparticles and the nanofibers could be observed in the electrospun PVDF web.

It has been well acknowledged that the microstructures of the electrospun PVDF web are relevant to the viscosity of the PVDF solution. As the viscosity of PVDF solution was increased from $18 \mathrm{wt} . \%$ to $23 \mathrm{wt} . \%$, the proportion of nanofiber in webs was increased due to the increased spinnability. Table 1 lists physical properties of the three electrospun PVDF webs. It can be observed that the PVDF nanofibers electrospun from $28 \mathrm{wt}$.\% solution had the lowest density of $0.202 \mathrm{~g} \cdot \mathrm{cm}^{-3}$ and the lowest thermal conductivity of $0.037 \mathrm{~W} \cdot \mathrm{m}^{-1} \cdot \mathrm{K}^{-1}$, compared to the microparticles and the combined microparticles and nanofibers electrospun from 23 wt. $\%$ and 18 wt. $\%$, respectively.

3.2. Morphologies of $\mathrm{SiO}_{2}$ Aerogel Composites Reinforced Electrospun PVDF Webs. Figure 2 shows optical and SEM image of the $\mathrm{SiO}_{2}$ aerogel composites reinforced with the three electrospun PVDF webs with different microstructures. The $\mathrm{SiO}_{2}$ aerogel composites were cut as the specimen in circles with the diameter about $12 \mathrm{~cm}$. It can be observed that the $\mathrm{SiO}_{2}$ aerogel composite specimens reinforced with the electrospun PVDF nanofibers and with combined PVDF microparticles and nanofibers showed intact integrity with a large size of diameter of $12 \mathrm{~cm}$, which is significantly bigger than that in the previous literature [21]. From Figures 2(e) and 2 (f) the $\mathrm{SiO}_{2}$ aerogel composite specimens reinforced with the electrospun PVDF nanofibers and with combined PVDF microparticles and nanofibers showed good flexibility even if they were bending into a circle. Therefore, the intact and flexible $\mathrm{SiO}_{2}$ aerogel composite specimens reinforced with the electrospun PVDF nanofibers and with combined PVDF microparticles and nanofibers have been firstly synthesized in this study. As a comparison, the $\mathrm{SiO}_{2}$ aerogel composite specimen reinforced with electrospun PVDF microparticles (Figure 2(a)) was fragile and readily turned into pieces while being bended. As the external bend force was exerted on the specimens, the specimen reinforced with microparticle was easily broken.

The description of the morphologies of the aerogel composites reinforced with the three microstructured PVDF webs is shown in Table 2. The intact morphology of the aerogel composites reinforced with PVDF nanofibers and the fragile morphology of that reinforced with PVDF microparticles imply that the electrospun PVDF nanofibers effectively improved the strength and the flexibility of the aerogels. It is because the electrospun PVDF nanofibers absorb the destructive energy and keep the integration of aerogel composite specimens. The second reason is that the diameter of the PVDF nanofibers is around $20 \sim 200 \mathrm{~nm}$ which is much closer to the size of holes and particles of the $\mathrm{SiO}_{2}$ aerogels. Moreover, as the electrospun PVDF nanofibers were added in the $\mathrm{SiO}_{2}$ aerogels, the $\mathrm{SiO}_{2}$ aerogels were separated into large quantity of small areas as shown in Figure 2(i). For the aerogel composites reinforced with electrospun PVDF nanofibers the induced tension difference between the interfaces of the nanofibers and the aerogel was reduced and the defects being bended were correspondingly decreased. As a result, the aerogel composites reinforced with electrospun PVDF nanofibers exhibited more perfect flexibility than the pure $\mathrm{SiO}_{2}$ aerogel and the $\mathrm{SiO}_{2}$ aerogel composites reinforced with electrospun PVDF microparticles.

Figure 3 shows the contact angle of the pure aerogel and the aerogel composites reinforced with electrospun PVDF webs. It can be observed that the contact angle of the pure aerogel is $139.0^{\circ}$. The contact angle of the aerogel composites was slightly reduced to $128.5^{\circ}-134.1^{\circ}$ as the electrospun PVDF webs were added. It may be because the added electrospun PVDF microparticles or nanofibers increase the surface roughness of the aerogels. The $\mathrm{SiO}_{2}$ aerogel composites reinforced with electrospun PVDF microparticles were still perfectly hydrophobic to water so that the aerogel composites could keep perfect thermal insulations even in moist environment.

\subsection{Thermal Properties of $\mathrm{SiO}_{2}$ Aerogel Composites Reinforced} with Electrospun PVDF Webs. Table 3 lists the thermal conductivities of the $\mathrm{SiO}_{2}$ aerogel composites reinforced with the electrospun PVDF webs with three different microstructures at room temperature. From Tables 1 and 3, it can be observed that the thermal conductivity of the electrospun PVDF nanofibrous webs was significantly decreased from $0.037 \mathrm{~W} \cdot \mathrm{m}^{-1} \cdot \mathrm{K}^{-1}$ and $0.027 \mathrm{~W} \cdot \mathrm{m}^{-1} \cdot \mathrm{K}^{-1}$ as the electrospun PVDF nanofibrous webs were filled with $\mathrm{SiO}_{2}$ aerogels. It is because the pores of the electrospun PVDF nanofibrous webs in the micron scale were filled with and separated by the aerogels to smaller pores in the nanometer scale. The gas thermal conductivity of the electrospun PVDF webs filled with nanoporous aerogels was significantly reduced since the size of the aerogel nanopores was even smaller than that of the molecular free path of the air in the pores. As a result 


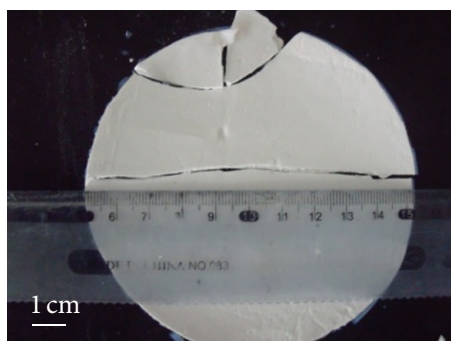

(a)

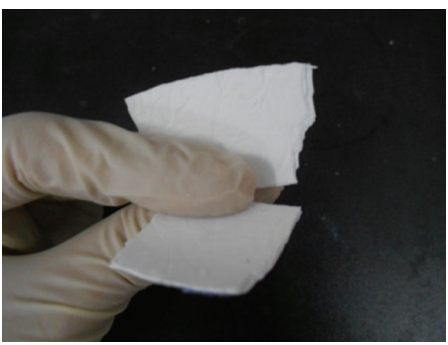

(d)

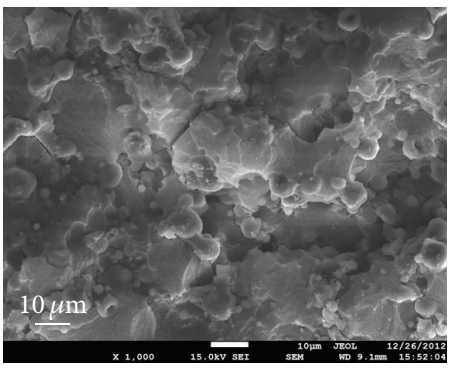

(g)

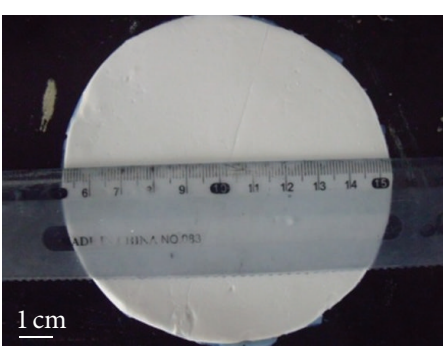

(b)

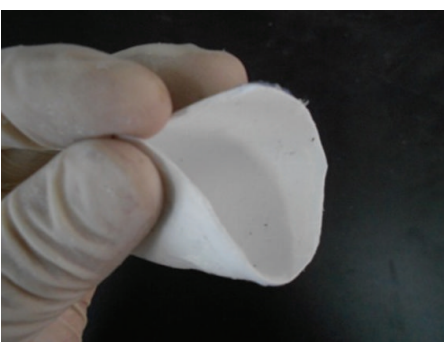

(e)

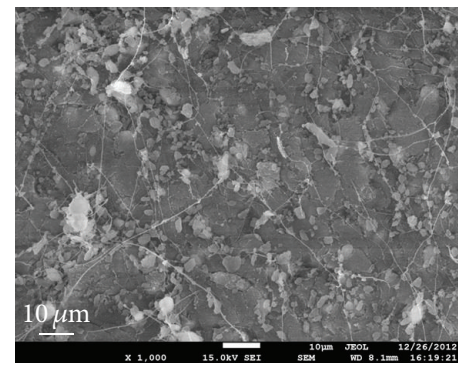

(h)

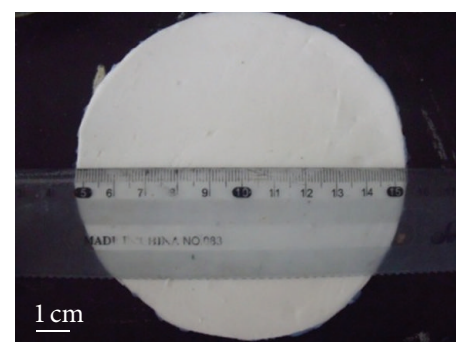

(c)

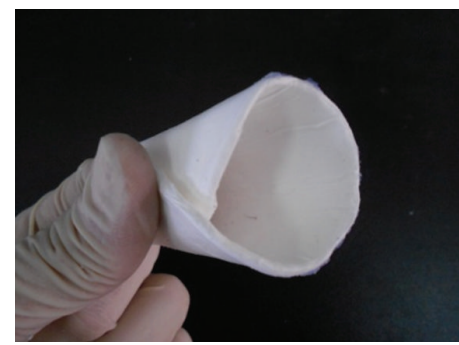

(f)

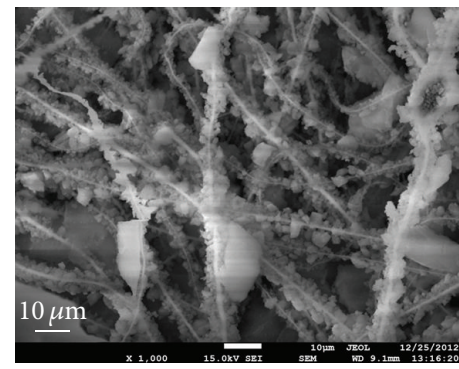

(i)

FIGURE 2: Morphology and flexibility of $\mathrm{SiO}_{2}$ aerogel composites reinforced with electrospun PVDF webs: (a, d, and g) microparticles; (b, e, and h) microparticles/nanofibers; (c, f, and i) nanofibers.

TABLE 2: Properties of $\mathrm{SiO}_{2}$ aerogel composites reinforced with electrospun PVDF webs.

\begin{tabular}{lccc}
\hline $\begin{array}{l}\text { Concentration } \\
\text { of PVDF } \\
\text { solution (wt.\%) }\end{array}$ & \multicolumn{2}{c}{$\begin{array}{c}\mathrm{SiO}_{2} \text { aerogel composites reinforced wih } \\
\text { electrospun PVDF web }\end{array}$} \\
\hline 18 & Integrity & Flexibility & $\begin{array}{c}\text { Density } \\
\left(\mathrm{g} \cdot \mathrm{cm}^{-3}\right)\end{array}$ \\
23 & Crack & Fragile & 0.277 \\
29 & Intact & Flexible & 0.235 \\
\hline
\end{tabular}

the aerogel composites reinforced with the electrospun PVDF webs had lower thermal conductivity than the electrospun PVDF webs.

The aerogel composites reinforced with the electrospun PVDF nanofibers yielded the lowest thermal conductivity of $0.027 \mathrm{~W} \cdot \mathrm{m}^{-1} \cdot \mathrm{K}^{-1}$ in all the three aerogel composites. The composite aerogel reinforced with the PVDF microparticles had the highest thermal conductivity of $0.039 \mathrm{~W} \cdot \mathrm{m}^{-1} \cdot \mathrm{K}^{-1}$, and the composite with combined PVDF microparticles and nanofibers had a moderate thermal conductivity of
$0.032 \mathrm{~W} \cdot \mathrm{m}^{-1} \cdot \mathrm{K}^{-1}$. It is because the electrospun nanofibers had smaller diameters and greater specific surface area which is advantageous to shield the heat radiation and reduce the effective thermal conductivity.

Figure 4 shows the thermal gravimetric analysis of the pure $\mathrm{SiO}_{2}$ aerogels and the $\mathrm{SiO}_{2}$ aerogel composites reinforced with the electrospun PVDF webs. It can be observed that the $\mathrm{SiO}_{2}$ aerogel composites have higher thermal stability below $475^{\circ} \mathrm{C}$ but lower thermal stability above $475^{\circ} \mathrm{C}$ than the pure $\mathrm{SiO}_{2}$ aerogels. The pure aerogel showed approximately around $10 \%$ weight loss in the temperature range of $350 \sim 475^{\circ} \mathrm{C}$, which is derived from the degeneration of $\mathrm{Si}-\mathrm{O}-\mathrm{C}_{2} \mathrm{H}_{5}$ group. The aerogel composites reinforced with the electrospun PVDF webs showed significant weight loss in the temperature range of $450 \sim 510^{\circ} \mathrm{C}$ owing to the degeneration of PVDF. The weight loss of the three aerogel composites reinforced by nanofibers, combined microparticles/nanofibers, and microparticles was $60 \%, 44 \%$, and $34 \%$ at $510^{\circ} \mathrm{C}$, respectively. Therefore, the aerogel composites reinforced by PVDF nanofibers showed better stability than that reinforced by PVDF microparticles. However, it should be noted that the PVDF materials including three electrospun 


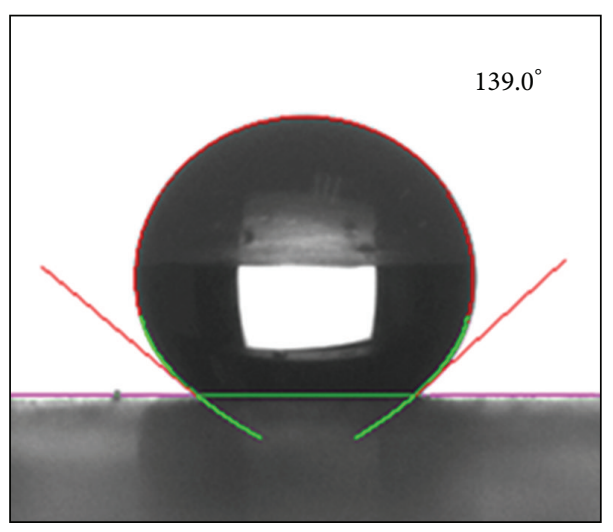

(a)

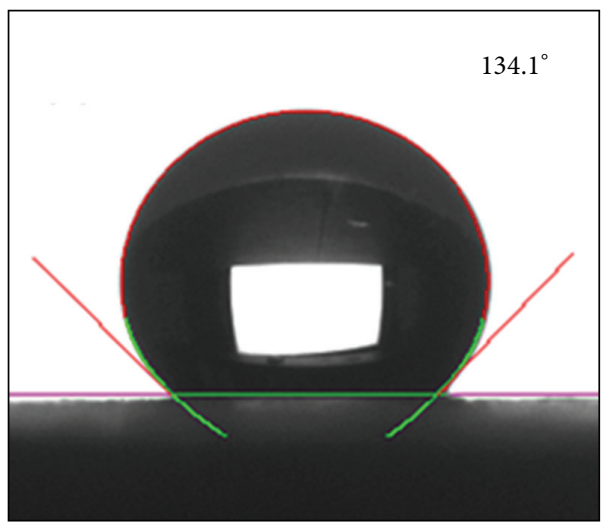

(c)

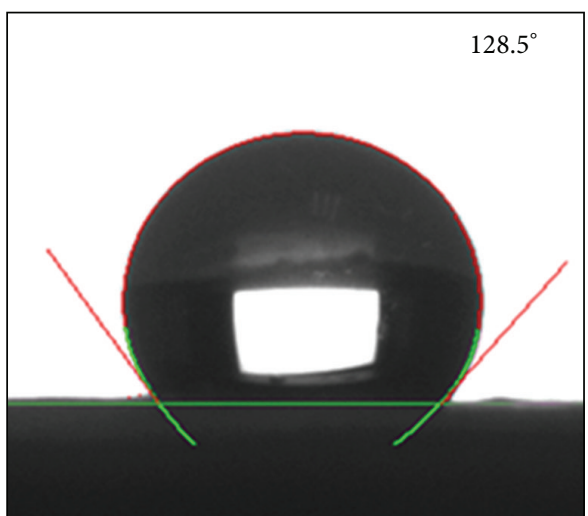

(b)

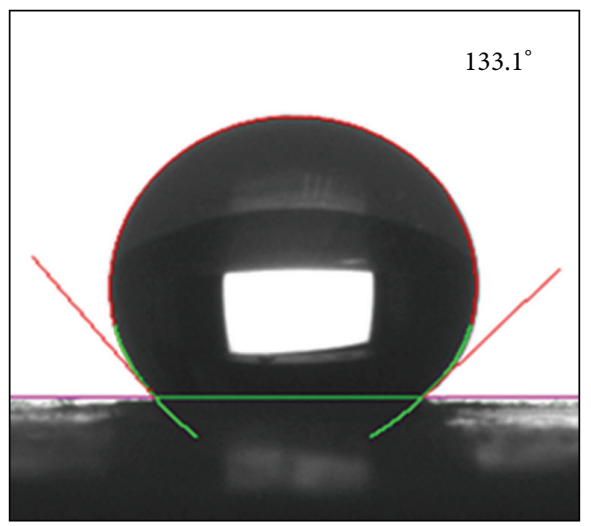

(d)

FIGURE 3: Contact angle of aerogel and aerogel composites reinforced with electrospun PVDF webs: (a) pure aerogel; (b) aerogel composites reinforced with electrospun PVDF microparticles; (c) aerogel composites reinforced with electrospun PVDF microparticles nanofibers; (d) aerogel composites reinforced with electrospun PVDF microparticles nanofibers.

PVDF webs may melt at $172^{\circ} \mathrm{C}$ although no noticeable weight loss exists. Therefore, the $\mathrm{SiO}_{2}$ aerogel composites reinforced with electrospun PVDF are suitable for the application in thermal insulation below $172^{\circ} \mathrm{C}$.

\subsection{Mechanical Properties of $\mathrm{SiO}_{2}$ Aerogel Composites} Reinforced with Electrospun PVDF Webs. Table 4 demonstrates the mechanical properties of the aerogel composites reinforced with different electrospun PVDF webs. It can be observed that the composites reinforced with electrospun PVDF nanofibers had the highest tensile strength of 1.03 MPa. The tensile strength of the composites reinforced with combined PVDF microparticles and nanofibers was $0.51 \mathrm{MPa}$ which was significantly less than that of the composites with nanofibers. Figure 5 illustrates the relation of the tensile strength and the deformation for the two aerogel composites. Compared to the combined microparticles/nanofibers reinforced composite, the nanofiber-reinforced composite exhibits higher yield strength. The nanofiber-reinforced composite experienced large deformation with a slight increase of the tensile strength while the combined microparticle/nanofiberreinforced composite was readily broken at a small deformation. It is because the nanofibers can easily absorb the power
TABLE 3: Thermal conductivity of aerogel composites supported by electrospun PVDF.

\begin{tabular}{lc}
\hline $\begin{array}{l}\text { Microstructure type of } \\
\text { electrospun PVDF }\end{array}$ & $\begin{array}{r}\text { Thermal conductivity of aerogel } \\
\text { composites }\left(\mathrm{W} \cdot \mathrm{m}^{-1} \cdot \mathrm{K}^{-1}\right)\end{array}$ \\
\hline Microparticle & 0.039 \\
Microparticle/nanofiber & 0.032 \\
Nanofiber & 0.027 \\
Without PVDF (pure aerogel) & 0.024 \\
\hline
\end{tabular}

exerted on the composite which leads an intact morphology of the aerogel composites.

Table 4 also shows that the aerogel composite reinforced with electrospun PVDF nanofiber had the compressive strength of $5.23 \mathrm{MPa}$, which is significantly higher than that reinforced with PVDF microparticle (2.74 MPa) and noticeably higher than that with the combined PVDF microparticle/nanofiber (4.56 MPa). As a comparison, the compressive strength of the pure $\mathrm{SiO}_{2}$ aerogels was $4.56 \mathrm{MPa}$. It can be deduced that the electrospun PVDF nanofibers significantly improved the compressive strength of the aerogels. Moreover, the electrospun PVDF nanofibers significantly 
TABLE 4: Mechanical properties of aerogel composite reinforced with electrospun PVDF webs.

\begin{tabular}{lccc}
\hline $\begin{array}{l}\text { Microstructures of electrospun } \\
\text { PVDF }\end{array}$ & \multicolumn{2}{c}{$\begin{array}{c}\text { Mechanical properties of aerogel composite reinforced with electrospun PVDF webs } \\
\text { Tensile strength (MPa) }\end{array}$} & $\begin{array}{l}\text { Compressive strength (MPa) } \\
\text { Bending strength (MPa) }\end{array}$ \\
\hline Microparticles & - & 0.74 & 0.12 \\
Microparticles/nanofibers & 1.03 & 4.56 & 0.79 \\
Nanofibers & - & 5.23 & 1.1 \\
Without PVDF (pure aerogel) & 0.75 & - \\
\hline
\end{tabular}

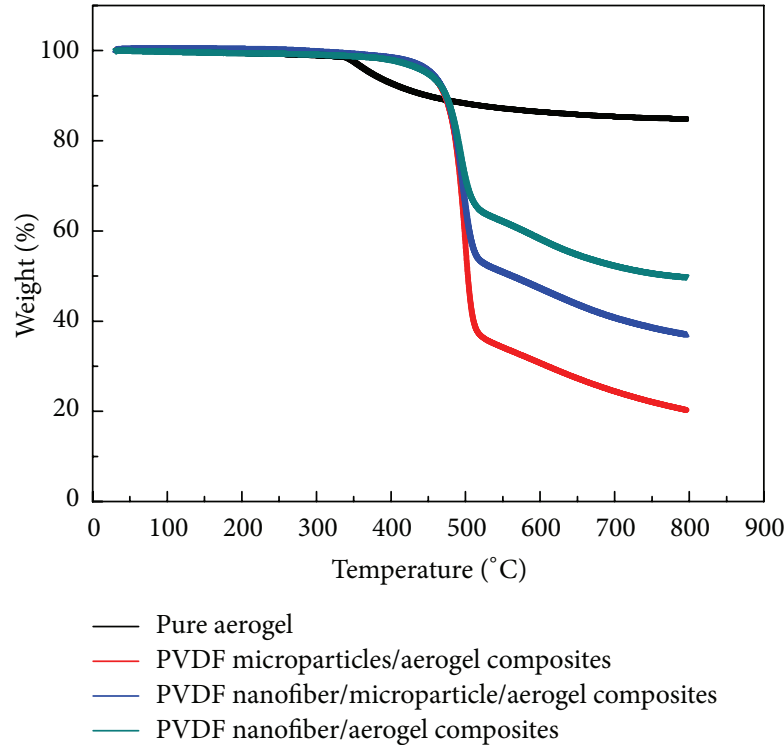

FIGURE 4: Thermal gravimetric analysis of pure aerogel and aerogel composites.

improved the bending strength of the aerogel composites up to $1.10 \mathrm{MPa}$ compared to $0.12 \mathrm{MPa}$ for the aerogel composites reinforced with PVDF microparticles. Therefore, the compressive strength and the flexibility of the $\mathrm{SiO}_{2}$ aerogels could be significantly improved by using the electrospun PVDF nanofibers as the reinforcements. It opens a promising way to improve the mechanical stability of the aerogels while keeping a low thermal conductivity via reinforcing the $\mathrm{SiO}_{2}$ aerogels by using electrospun nanofibers.

\section{Conclusions}

Flexible aerogel composites, with a size of $12 \mathrm{~cm}$ diameter and a low thermal conductivity up to $0.027 \mathrm{~W} \cdot \mathrm{m}^{-1} \cdot \mathrm{K}^{-1}$, were successfully synthesized via electrospinning and sol-gel processing. Three $\mathrm{SiO}_{2}$ aerogel composites reinforced with different electrospun PVDF microstructures (e.g., microparticles, nanofibers, combined microparticles, and nanofibers) were obtained and the effects of the electrospun PVDF microstructures on the thermal and mechanical properties of the aerogel composites were evaluated. The results show that the aerogel composite reinforced with the electrospun PVDF nanofibers had the lowest thermal conductivity and the greatest mechanical strength. The electrospun PVDF nanofiber supported

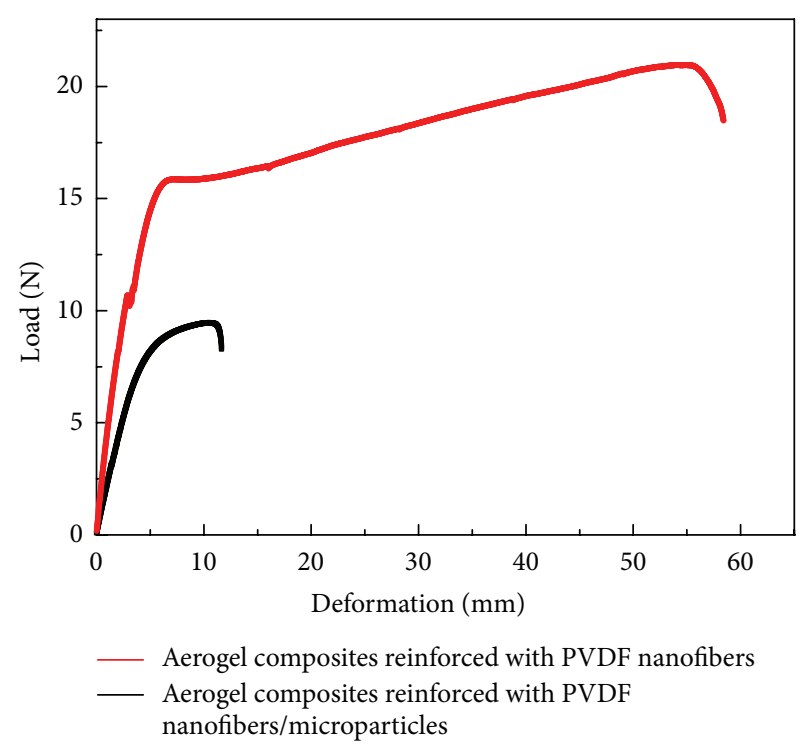

FIGURE 5: Stretching stress-deformation curves of aerogel composite.

$\mathrm{SiO}_{2}$ aerogel composites that had a low thermal conductivity of $0.027 \mathrm{~W} \cdot \mathrm{m}^{-1} \cdot \mathrm{K}^{-1}$ which was slightly higher than the pure aerogel. However, the compressive strength and the flexibility of the aerogel composites were significantly improved via the reinforcement of the electrospun PVDF fibers. It opens a controllable way to improve and engineer the mechanical properties of the aerogel composites with low thermal conductivity via reinforcing the aerogels by using electrospun nanofibers.

\section{Acknowledgments}

This research was supported by Key Project of Ministry of Education of China (211130), Guangdong Natural Science Foundation of China (S2011010003429), Guangdong Undergraduate Innovative Experiment Project of China (1107811020), Guangdong Major Science and Technology Project of China (2012A010800033), and Yangcheng Scholars Research Project of China (10A038G).

\section{References}

[1] J. Fricke and T. Tillotson, "Aerogels: production, characterization, and applications," Thin Solid Films, vol. 297, no. 1-2, pp. 212-223, 1997. 
[2] A. C. Pierre, "History of aerogels," in Aerogels Handbook, M. A. Aegerter, Ed., pp. 3-20, Springer, London, UK, 2011.

[3] R. Baetens, B. P. Jelle, and A. Gustavsen, "Aerogel insulation for building applications: a state-of-the-art review," Energy and Buildings, vol. 43, no. 4, pp. 761-769, 2011.

[4] D. M. Smith, A. Maskara, and U. Boes, "Aerogel-based thermal insulation," Journal of Non-Crystalline Solids, vol. 225, no. 1-3, pp. 254-259, 1998.

[5] J. M. Schultz, K. I. Jensen, and F. H. Kristiansen, "Super insulating aerogel glazing," Solar Energy Materials and Solar Cells, vol. 89, no. 2-3, pp. 275-285, 2005.

[6] T. Woignier, J. Reynes, A. Hafidi Alaoui, I. Beurroies, and J. Phalippou, "Different kinds of structure in aerogels: relationships with the mechanical properties," Journal of NonCrystalline Solids, vol. 241, no. 1, pp. 45-52, 1998.

[7] H. Lu, H. Luo, and N. Leventis, "Mechanical characterization of aerogels," in Aerogel Handbook, pp. 499-535, Springer, New York, NY, USA, 2011.

[8] N. Leventis, C. Sotiriou-Leventis, G. Zhang, and A. M. M. Rawashdeh, "Nanoengineering strong silica aerogels," Nano Letters, vol. 2, no. 9, pp. 957-960, 2002.

[9] Y. Liao, H. Wu, Y. Ding et al., "Engineering thermal and mechanical properties of flexible fiber-reinforced aerogel composites," Journal of Sol-Gel Science and Technology, vol. 63, no. 3, pp. 445-456, 2012.

[10] Z. H. Zhang, J. Shen, X. Y. Ni et al., "Preparation and characterization of hydrophobic silica aerogels doped with fibers," Rare Metal Materials and Engineering, vol. 37, no. 2, p. 4, 2008.

[11] A. Karout, P. Buisson, A. Perrard, and A. C. Pierre, "Shaping and mechanical reinforcement of silica aerogel biocatalysts with ceramic fiber felts," Journal of Sol-Gel Science and Technology, vol. 36, no. 2, pp. 163-171, 2005.

[12] J. Feng, C. Zhang, J. Feng et al., "Carbon aerogel composites prepared by ambient drying and using oxidized polyacrylonitrile fibers as reinforcements," ACS Applied Materials \& Interfaces, vol. 3, no. 12, pp. 4796-4803, 2011.

[13] K. Finlay, M. D. Gawryla, and D. A. Schiraldi, "Biologically based fiber-reinforced/clay aerogel composites," Industrial \& Engineering Chemistry Research, vol. 47, no. 3, pp. 615-619, 2008.

[14] J. Yang, S. Li, Y. Luo, L. Yan, and F. Wang, "Compressive properties and fracture behavior of ceramic fiber-reinforced carbon aerogel under quasi-static and dynamic loading," Carbon, vol. 49, no. 5, pp. 1542-1549, 2011.

[15] D. H. Reneker and A. L. Yarin, "Electrospinning jets and polymer nanofibers," Polymer, vol. 49, no. 10, pp. 2387-2425, 2008.

[16] D. Li, J. T. McCann, Y. Xia, and M. Marquez, "Electrospinning: a simple and versatile technique for producing ceramic nanofibers and nanotubes," Journal of the American Ceramic Society, vol. 89, no. 6, pp. 1861-1869, 2006.

[17] A. Greiner and J. H. Wendorff, "Electrospinning: a fascinating method for the preparation of ultrathin fibers," Angewandte Chemie, vol. 46, no. 30, pp. 5670-5703, 2007.

[18] D. Zhang and J. Chang, "Patterning of electrospun fibers using electroconductive templates," Advanced Materials, vol. 19, no. 21, pp. 3664-3667, 2007.

[19] D. Li and Y. Xia, "Direct fabrication of composite and ceramic hollow nanofibers by electrospinning," Nano Letters, vol. 4, no. 5, pp. 933-938, 2004.

[20] J. T. McCann, D. Li, and Y. Xia, "Electrospinning of nanofibers with core-sheath, hollow, or porous structures," Journal of Materials Chemistry, vol. 15, no. 7, pp. 735-738, 2005.
[21] L. Li, B. Yalcin, B. N. Nguyen et al., "Flexible nanofiberreinforced aerogel (xerogel) synthesis, manufacture, and characterization," ACS Applied Materials \& Interfaces, vol. 1, no. 11, pp. 2491-2501, 2009. 

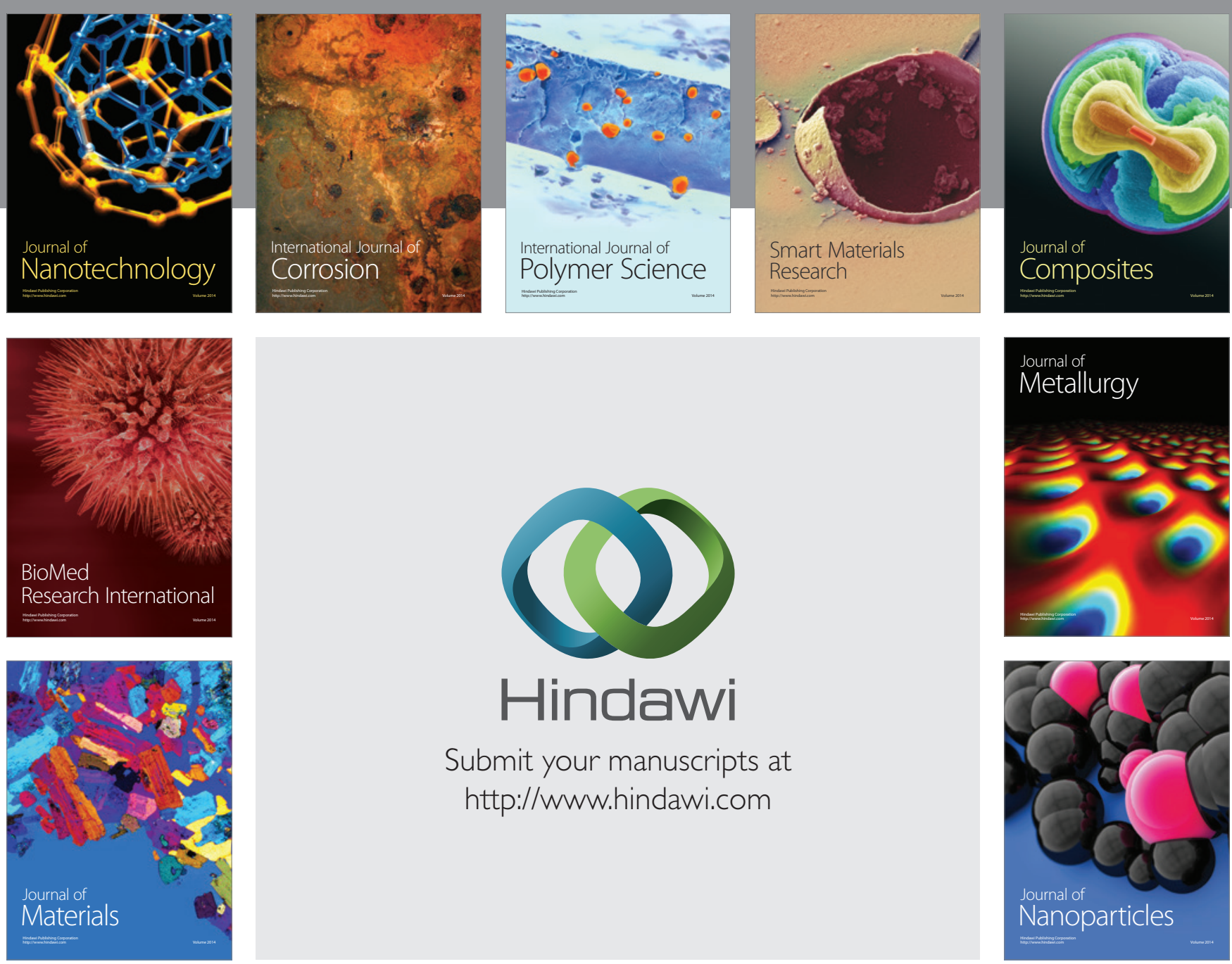

Submit your manuscripts at http://www.hindawi.com
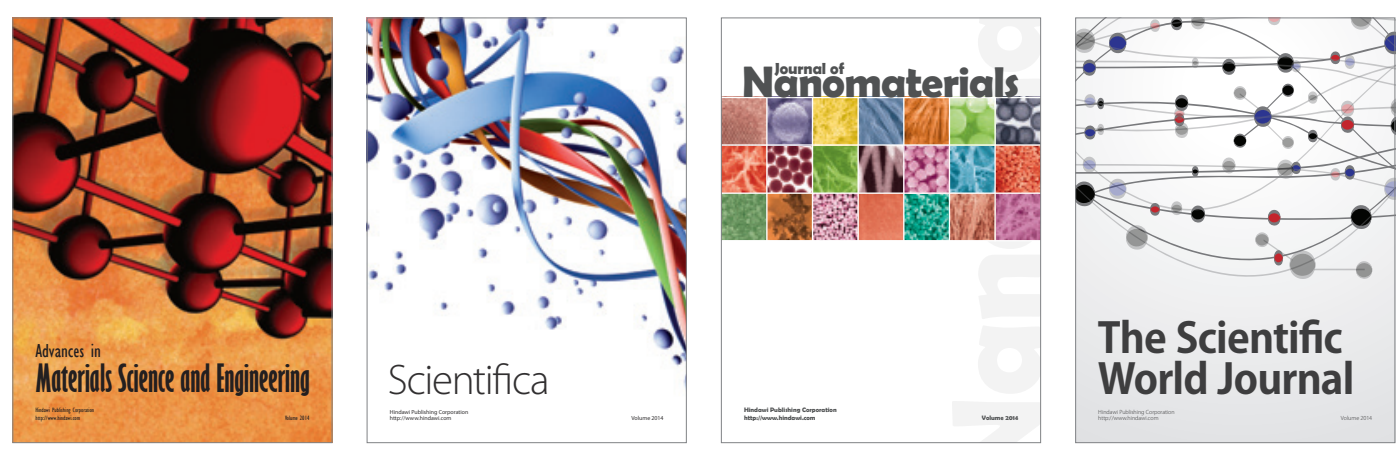

\section{The Scientific World Journal}
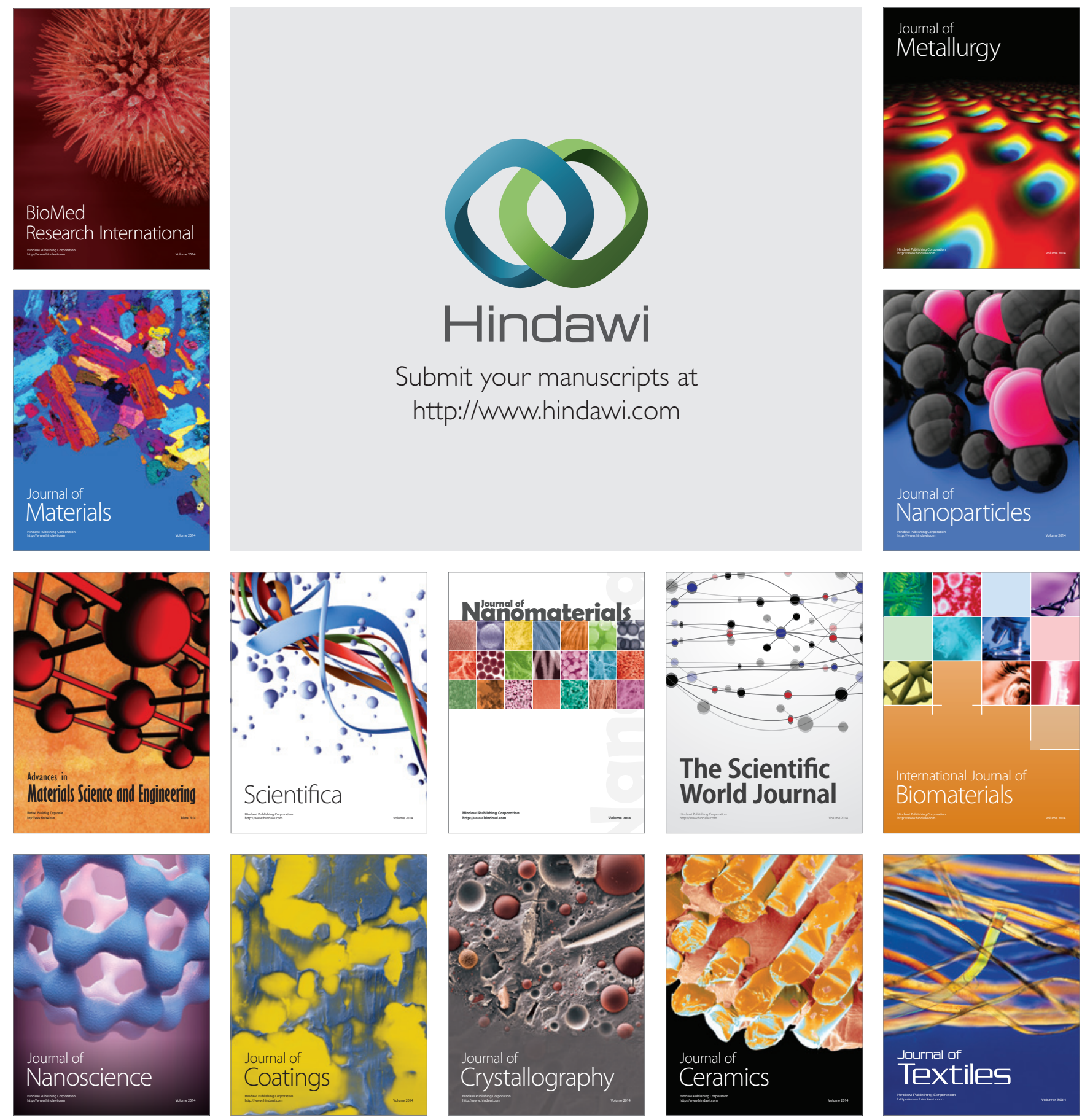